\title{
Research on Accounting Information System Based Big Data
}

\author{
Menghan $\mathrm{Li}^{1, *}$ \\ ${ }^{1}$ School of Information Technology and Electrical Engineering (ITEE), the University of Queensland \\ *Corresponding author. Email: menghan.li1@uqconnect.edu.au
}

\begin{abstract}
Nowadays, society is gradually entering the era of big data, which can help people make correct judgments and help enterprises manage rationally. The concept of big data has been gaining increasing attention in recent years, and the application of big data technology in a wide range of industries is now just gaining momentum, especially in accounting, which is playing an increasingly important role. However, big data is still in its infancy and has not yet reached a very mature stage. There are still many challenges to overcome, which means that the security of accounting data still faces certain risks. This article analyses the technologies that can be combined with the development of accounting information systems in the era of big data, analyses some possible risks in the accounting information system and proposes corresponding preventive measures.
\end{abstract}

Keywords: Big data, Cloud computing, Accounting information system, Measurement

\section{INTRODUCTION}

\subsection{The accounting information}

Big data refers to a massive amount of information resources with diverse sources, complex and numerous types, faster processing speed, and whose value can be recycled many times, with the characteristics of large amount, diversity, high speed, and low-value density. Big data includes many types of data. Currently, the collection of accounting information is mainly based on structured data. At the same time, unstructured data is crucial to business decision-making. Therefore, in the era of big data, companies need to collect unstructured data, increase the proportion of unstructured data collection, and interpret and understand these data to improve decision-making accuracy.

Accounting information plays a vital role in business activities, has essential value and significance in business economic decision-making, and has a significant and farreaching impact on the economic operating system. In the context of continuous economic and social development and the influx of the trend of information and intelligence in social development, the first characteristic of enterprise financial data reflected in the era of big data is the massive amount of data, and the data revealed by financial statements is several times or even dozens of times more than the previous data of the enterprise. Therefore, big data technology to improve the quality of accounting information is an issue worth studying.

\subsection{Accounting Information System}

AIS (Accounting Information System) is an application software specially designed for accounting data processing. As an additional tool of the accounting information system, AIS is a necessary guarantee for effective management and decision-making of enterprises and an important platform for enterprises to analyse the market. At the same time, it has the function of grasping the operating status of the enterprise. It is also an essential tool for the enterprise to grasp the operating status of corporate accounting and financial statement data generation. At present, many enterprises' accounting information systems are still not perfect and cannot effectively assist in enterprise management, analysis, and decision-making. Through the application of big data technology, the accounting information system of enterprises can be improved and made more effective.

The financial information system collects, stores, and processes financial data to analyse the business activities and results of the enterprise and output financial information. After the financial information system completes accounting, the management information system begins to analyse relevant data, provide practical 
information, and make intelligent decisions. The financial information output by the financial information system is transmitted to the management information system and analysed to support enterprise management and decision-making.

\section{CLOUD COMPUTING IN AIS}

In the era of big data, traditional accounting system models cannot effectively analyse and process financial data, so cloud computing technology tools are needed. First, cloud computing has super data analysis and processing capabilities that can process massive amounts of data in a short period and accurately analyse and reveal the characteristics and internal connections between financial data and information. Second, cloud computing technology can achieve inter-enterprise. As well as the resource sharing between various departments within the enterprise, a complete analysis and interpretation of enterprise financial data can be achieved without increasing operating and management costs. Furthermore, cloud computing technology can realize resource sharing between enterprises and internal departments and complete analysis and interpretation of enterprise financial data without increasing operating and management costs.

The core function of cloud computing technology is the virtualization of accounting information and cloud storage services. The virtualization of financial data is one of the core technologies for realizing accounting data in the cloud. Virtualization integrates enterprise financial data's computing and analysis processes to improve the ability to summarise and evolve data analysis. Virtualization of all types of data stored in the cloud maximizes financial accounting information and data resources and improves the efficiency of using server resources. In addition, the virtualization of financial data can call up financial data quickly based on different commands from users and find the logical relationships hidden behind the big data.

The traditional accounting information processing system is not powerful enough, and the data processing is inefficient, and to a large extent, requires the manual cooperation of financial staff, which significantly reduces the efficiency of information processing. Under such circumstances, the accounting information system can only provide managers with historical and empirical data analysis. However, the inability to achieve real-time control over the business management process, financial management process and financial decision-making often delay the best time to deal with risks. The accounting information processing system based on cloud computing technology improves the coordination and data sharing between various enterprise departments and solves the timeliness of accounting information. The ultimate goal of the cloud computing computerized system model study is to deal with the diverse output of accounting information systems and provide users of financial information with an accurate and complete basis for decision-making.

\subsection{Input and storage of accounting information}

After the accounting information is collected and entered, the data should first be stored in the cloud and stored by category to ensure subsequent data classification smooth processing. After data entry, the accounting information data must be classified and stored in the company's temporary database. A real-time connection between the company database and the cloud database is established to ensure that the company's accounting data is uploaded to the cloud in time for emergency needs. The company or its data requester uses them. The entry and storage of cloud accounting information adopt a matter-driven model to record the complete entry information. When the information needs to be recalled, the instructions can be completed by simply entering the relevant code. This driven approach aggregates all primary events into an event database and forms a primary event database according to specific rules.

\subsection{Accounting information processing}

The cloud computing platform has various financial accounting data and information processing capabilities. After all accounting information is uploaded to the cloud database, it is again classified according to the type of information in the knowledge base, method library, and model library. The knowledge base contains many accounting standards, various rules related to financial accounting, various account names, etc. There are two commonly used methods: the method database is used for accounting information processing methods, such as mathematical methods, statistical analysis methods, etc., and the model database is used for various data prediction models, investment and financing management models, etc.

\subsection{Data output from accounting information system}

The human-computer interaction of cloud-based accounting information systems is more powerful, and the output of data and information selects the basic event trigger model, which is easy to use. Users need to input their accounting information needs, and the system will be able to provide targeted and diverse accounting information. Cloud-based computing is more flexible in terms of human-computer interaction, solving information asymmetry among data users, and better meeting the needs of different types of users. Cloud computing technology is the best way to deal with massive amounts of data. Under the cloud computing 
framework, data collection, entry, storage, and diversified output are effectively solved, and the efficiency and accuracy of computerized accounting information processing and recall are improved.

\section{RISKS OF AIS UNDER BIG DATA}

\subsection{Inadequate system functionality}

An accounting information system is a financial information system and has the function of a management information system. Simple bookkeeping and accounting is not the ultimate goal of an accounting information system but a critical tool to support enterprise management and decision-making. The information generated by the information system is passed to the management information system, which analyses it to support management and decision-making. Data preparation and analysis are essential to achieve this goal. This is a feature that financial information systems do not have because they focus on managing analytics, analysing relevant data, providing practical information, and making informed decisions. Most business information systems currently do not address data preparation and analysis issues, resulting in incomplete functions of commercial accounting information systems to provide commercial services.

\subsection{Security of accounting information in transmission and application}

As the application of big data technology in the accounting field continues to expand, how to improve the security of accounting information in the process of transmission and application has become the focus of enterprise development. In the enterprise development process, it is necessary to continuously monitor the accounting information system's user, financial, and business data of the accounting information system continuously and dynamically, and take necessary protective measures to reduce malicious tampering from outside.

While the cloud accounting system is running, various financial data is transmitted through the network. As the carrier changes from the original paper version to data, during the transmission process, it is easy for some unscrupulous elements to steal and tamper with the enterprise data, causing certain economic losses to the enterprise. On the other hand, the software developers of the accounting-information-system pay attention to protecting their products in the development process, encrypt the development software into encryption, and neglect the encryption of the data transmitted in the accounting information system. As a result, the security effectiveness of the accounting information system is low, and the risk of data leakage is high.

\subsection{Lack of multi-skilled accounting talent}

Accounting information involves accounting, computer technology, management science, and other fields of knowledge. The successful implementation of enterprise accounting information technology depends on the combination of computer and financial talents. Talent is an integral part of the construction of accounting information technology. In terms of actual development, some accountants do not have high skills and insufficient business skills, which in essence results in them being inefficient in the actual work process and unable to master excellent management experience and methods promptly. In the use of financial software, there is no clear understanding of financial software, and it is easy to make operational mistakes. Some mistakes in thinking have caused errors in the use of the software. Therefore, the relevant management personnel of the enterprises must constantly train the technical level of the accounting staff and make them aware of all the severe consequences that the problem may bring in the actual working process to ensure that their practical operation ability can be synchronized with the development trend.

\section{MEASUREMENTS TO PREVENT AIS RISKS}

\subsection{Enhanced system security}

When enterprises carry out information construction, they need to strengthen the security of the information platform system and provide more targeted maintenance strategies through the analysis of security risks related to enterprise information construction. Information platform management specifically includes the following.

In daily use, users must pay close attention to and record the abnormal situation in the operation of the software, install and modify patches on time, regularly scan and analyse the software system, and solve the problem of software vulnerabilities.

Antivirus software is commonly used for antivirus, while network antivirus software is to prevent network viruses. Antivirus software is one of the most effective means of preventing and controlling computer viruses, but no antivirus software can stop all computer viruses. Therefore, we need to select and update our antivirus software at any time to protect our computer systems effectively. Corporate network security and campus environmental network security can protect the environment from viruses through antivirus software.

Back up necessary data regularly. Regular data backups help protect user's business's critical data. Businesses should back up their data regularly and classify it as the case may be. Some critical data tends to have a high backup frequency, ensuring that critical data 
can be repaired on time after a system problem or virus attack. Companies can also secure the data of their accounting information systems by backing up system areas and backing up disks for new installations.

The security management of user identity authentication should be done well. Enterprise cloud computing information service platforms can select many certification bodies according to actual needs, form a sound operation and viewing protection mechanism, improve the security of enterprise cloud computing application systems.

\subsection{Increasing the development of professional talent}

In the information age, the requirements of enterprises for accounting staff are not only limited to the professional ethics and basic accounting knowledge of the practitioners, but also require them to have information technology literacy, familiarity with the business areas of accounting information, information retrieval skills and a strong sensitivity to accounting information. Therefore, it is imperative to train accounting practitioners in information technology knowledge.

In addition to this, the accounting system driven by big data stores a vast amount of information. The professional ethics and professional competence of inhouse accounting staff are of great importance to the safe development of the accounting information system. Given the familiarity and understanding of the system, if the system is damaged, it will significantly impact the enterprise and the entire industry. Therefore, strengthening the training of accountants is the key to improving current development problems. The personnel learning process strengthens system security knowledge and proficient application to identify potential risks and find practical solutions accurately. Therefore, we should pay attention to the construction of composite accounting talents, adhere to the continuing education of accounting personnel, improve the knowledge structure, improve the level of computer applications, and train composite talents.

\section{CONCLUSION}

This paper explains the impact of the rapid development of the information age on accounting information. The emergence of cloud computing technology has provided a new solution and application platform for the management and integration of massive accounting information, which has prompted a fundamental change in the construction of enterprise accounting information systems and will undoubtedly bring good prospects for the development of enterprise Informa ionization.
It also identified many problems and challenges in the security of accounting information technology, which are not currently sufficient to address. The technical answers identified and described in this work can also be considered future research directions in the AIS field. Studying the impact of information technology on enterprise accounting has dramatically improved the professional level of accounting personnel and promoted the efficient and rapid development of enterprises. It is essential in both the field of information and the field of finance. The emergence of cloud computing technology provides a new solution and application platform for the management and integration of massive accounting information, which leads to fundamental changes in the construction of enterprise accounting information systems. It will bring good prospects for the development of enterprise information.

\section{REFERENCES}

[1] F. Belfo and A. Trigo, "Accounting information systems: Tradition and future directions," Procedia Technology, vol. 9, pp. 536-546, 2013.

[2] A. Bhimani and L. Willcocks, "Digitisation,' Big Data and the transformation of accounting information," Accounting and Business Research, vol. 44, no. 4, pp. 469-490, 2014.

[3] E. Huerta and S. Jensen, "An accounting information systems perspective on data analytics and Big Data," Journal of information systems, vol. 31, no. 3, pp. 101-114, 2017.

[4] J. V. Villa, M. H. Sharairi, A. C. Navarrete, and G. F. I. Sancho, "An Accounting Information Systems Perspective On Data Analytics And Big Data During 2015-2020," Turkish Journal of Computer and Mathematics Education (TURCOMAT), vol. 12, no. 5, pp. 509-514, 2021.

[5] Y. Wang, "Research on Security of Accounting Information System in the Era of Big Data," in Journal of Physics: Conference Series, 2021, vol. 1881, no. 4: IOP Publishing, p. 042030.

[6] M. Weng and D. Weng, "Discuss the Accounting Information Risks and Preventive Measures Based on Big Data," in 2021 2nd International Conference on Modern Education Management, Innovation, and Entrepreneurship and Social Science (MEMIESS 2021), 2021: Atlantis Press, pp. 110114. 